\title{
THE ROLE OF MODERN BUILDING MATERIALS IN REDUCING ENERGY CONSUMPTION AND ENVIRONMENTAL POLLUTION
}

\author{
Elham Ghaffarlu ${ }^{\star{ }_{1}}$ and Shabnam Ghaffarlu ${ }^{2}$
}

\author{
Young Researchers and Elite Club, Ilkhchi branch, Islamic Azad University, Ilkhchi, Iran
}

Original Article

PII: S238315531900001-8

Received: 20 Dec. 2018

Accepted: 15 Apr. 2019

Published: o5 Jun. 2019

Corresponding author:

E-mail: sh-ghaffarlu@gmail.com

\begin{abstract}
In today's life, human population growth is accompanied by an increase in fossil fuel consumption, which is a major source of conservation in nature. Energy conservation is one of the principles of sustainable architecture in which the architect is required to design the building in such a way as to meet the building's requirements Fossil fuels are minimized, but since the need for unconditional comfort and convenience has led to a growing need for energy in the domestic and industrial sectors, architects and designers of the building have taken it to meet this need and in parallel It considers the protection of the environment and fossil fuels. Today, human beings are pushing for better solutions and better solutions. For optimal use of energy, the use of intelligent building materials and materials in today's buildings is a timely response to changes that make the building more durable and enhances. It is possible that the discovery of intelligent materials is practical for architects to use this material, which is the most important advantage. They are encouraging the optimization and intelligent management of energy. The object of the study is to investigate the present research through objective observation. In fact, research has been conducted on the basis of a rational method and an analysis and description of the achievement of the research objectives. The method and method used are the research of the library method and the examination of written documents.
\end{abstract}

KEYWORDS: Modern Materials, Smart Materials, Reducing Energy Consumption, Reducing Environmental Pollution

\section{INTRODUCTION}

Given the increasing population growth in recent years, the necessity of removing housing construction from the traditional way, and the use of modern materials and methods of industrialization has become more evident. One of the most important parameters affecting the increase of productivity in the building industry is the possibility of using modern materials and new methods of construction in different geographic conditions in terms of technical facilities in that area [1]. Materials used in buildings have a significant role to play in building the right architecture based on sustainable architecture and environmental protection [2]. Considering the reduction of energy reserves in the current situation, the use of modern and intelligent materials that are effective in reducing energy in buildings is one of the essential measures in the field of construction [3, 4]. In fact, the selection of modern and appropriate materials and equipment will reduce energy consumption and further health It contributes to the environment. Because of this, the materials reduce the amount of fuel consumed in buildings, reduce emissions of air and greenhouse gases, and cause less damage to the environment and energy and resources [5-8]. At present, the problem design and the necessity of the research have been addressed and then the goals and method of research is used.

The main objectives of this research is focusing architects and designers on the use of modern materials in order to reduce energy consumption and reduce environmental pollution in the design and implementation of the building, it is clear that replacing modern materials rather than traditional materials will be a major step towards reducing environmental pollution. In this research, analyticaldescriptive method has been used. The method and tool used in the research are library method and review of written documents. Modern building materials

\section{METHODOLOGY}

\section{Problem statement and research necessity}

In human life today, population growth is associated with an increase in the consumption of fossil fuels, which is a major source of conservation in nature [9]. Energy conservation is one of the
2019, Scienceline Publication

JAAS Journal of Art and Architecture Studies ISSN 2383-1553 J. Art Arch. Stud. 8(1): 01-06, June 05, 2019 
principles of sustainable architecture in which the architect is required It should be designed in such a way that the building's requirements for fossil fuels are minimized [2]. Nowadays, with the traditional materials often used in buildings, it does not meet the economic conditions and the density of building of modern cities, and the contradictions created by the impact Negative in terms of energy efficiency, it brings about a long time It is necessary, with the advent of modern materials that meet the economic and congestion of cities, to deal with energy losses in buildings and reduce the pollution caused by it for the environment.

\section{RESULTS AND DISCUSSION}

\section{Accoya}

Accoya wood is the result of research and studies over 80 years old. As a result of the combination of acetic processing and the implementation of the exclusive technology of cutting edges, the high quality wood produced by the brand Accoya is extremely suitable for outdoor applications. One of the uses of Accoya as a hinge on the structure is different buildings and buildings. This unique wood is used in outdoor applications and even in water. The wood treated with stelazing technology (Accoya wood) is one of the few woods that will last long years into the water without any worries. Due to the waterproof nature of the Accoya wood, this product has many applications such as window-to-door, deck-to-facade and bridges.

Extensive research and experiments on Accoya wood have shown that this unique wood will not bring any harm to the environment and will have a great contribution to the conservation of the environment. The use of Accoya in the woodwork has a significant impact on environmental preservation. Due to its endurance and durability, Accoya wood is also replaceable with non-resistant wood.

\section{Accoya wood feature}

Accoya wood uses much less energy in its production and use compared to other building materials such as cement, glass and aluminum, Compared to other materials such as aluminum, PVC and tropical hardwood (tropical hardwood from unstable forests supply). The Accoya leaves emit less greenhouse gas emissions. Accoya wood is more durable compared to wood such as Spruce and Red Meranti tropical hardwood, which are used as construction materials. The price of Accoya wood is more economical due to its unique features compared to the wood.
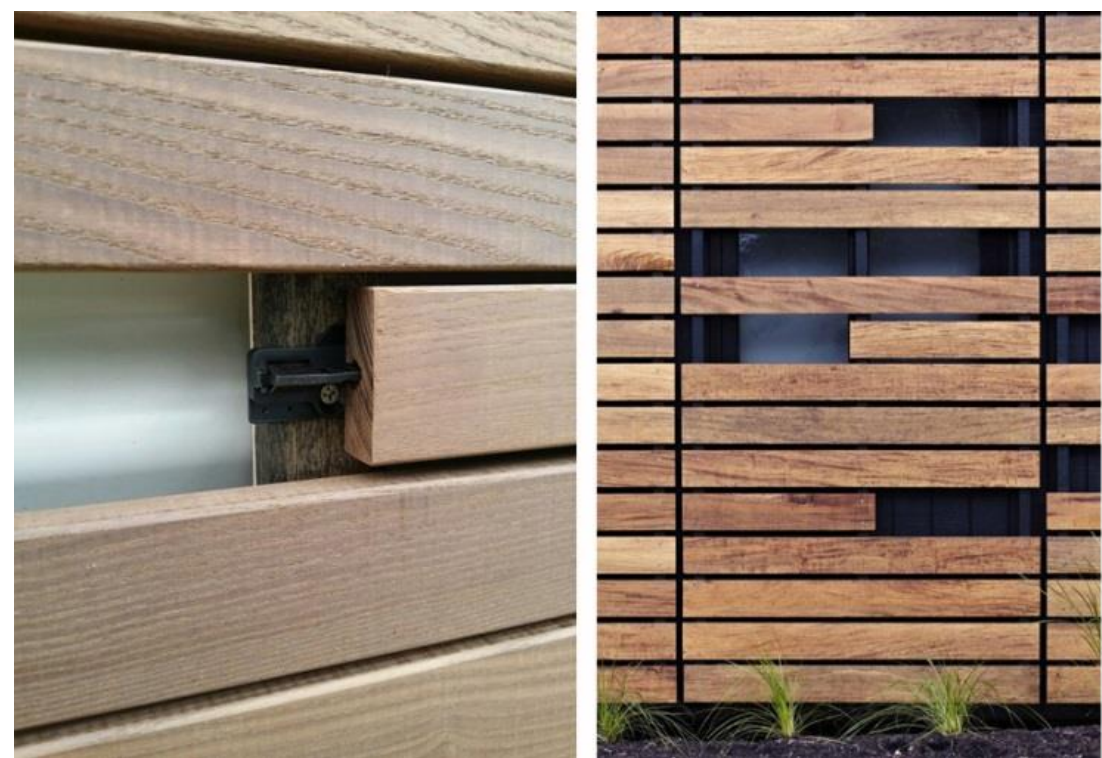

Figure 1. Accoya wood

\section{EQUITONE}

It is made of cement fibers and is used in the facade of the building. Cement fiber is made of cellulose and mineral materials reinforced by a matrix, which has a smooth and opaque fog. The EQUITONE Moda is manufactured at a maximum panel of 125 by $310 \mathrm{~cm}$ and can be used comfortably in any shape or dimension and in modular form.
EQUITONE cement fibers have eating, perforating, and eating ability. Fixing methods include rivets, screws, glue and invisible fittings on wooden or metal frames. Creative architects and designers use EQUITONE cement fibers in interior design. EQUITONE has a wide range of color spectra, which is also suitable for interior design projects. 


\section{Performance and reliability}

EQUITONE cement fibers are non-flammable and have a shelf life of over 50 years (Figure 2).
The Rainscreen views made with EQUITONE are thinner and lightweight, yet highly durable, which reduces energy and raw material consumption.
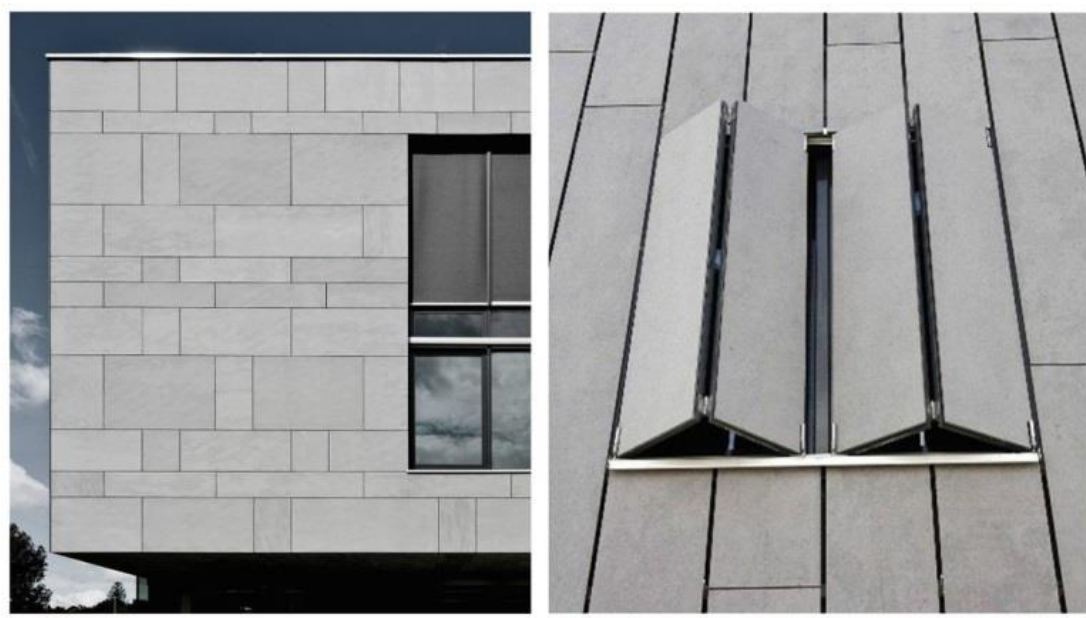

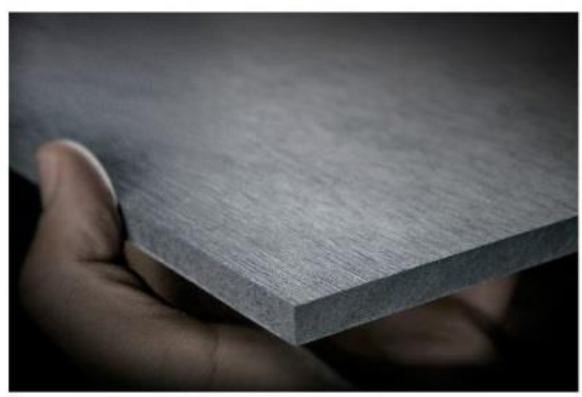

Figure 2: Cement fibers

\section{Wall panel sandwich}

It is a kind of building material that has two layers of electrostatic, scratch-resistant, different thicknesses and desired lengths in the interior and exterior facades, which are used with a grooved monolithic and slit-free design, and the sliding edges during installation make it more beautiful and more robust. The wall is injected between them and used to cover the wall is called wall panel sandwich.

\section{Advantages of wall panel sandwich}

Moisture and cryogenic insulation, soundproof and resistant to moisture, cold weather moisture, heat, moisture, weatherproof, rust, chemicals, vermin, colour variety, washable, hygienic, lightweight sandwich panel and ultimately weight loss, The speed of implementation and reducing the cost of prolonged projects, earthquake resistance, increasing the life of the building and facilities, and the ability to move and rebuild it from the sandwich panel wall panel.

\section{Wallboard sandwich}

To cover the walls of the cellars, sport niches, prefabricated pre-fabricated suites, villa buildings, sports halls and sports grounds, laboratory rooms and food industries.

\section{Composite aluminium panel}

Covering the building with large aluminum or aluminum panels of $4 \mathrm{~mm}$ thick thickness, consisting of two layers of aluminum sheet, and their inner core made of polyethylene or anti-fire minerals and a coating of PVDF resin (Aluminum composite Panels) is read.

\section{Advantages of aluminium composite panel system}

The beauty and luminance of the aluminium facade, easy maintenance, sound and sound isolation, ultra-infinite color variations, superb stability and long life in a variety of atmospheric conditions, the ability to select and execute very complex levels in the arc, the possibility of All types of machining, bending, roof piercing, quick and precise installation, excellent strength against earthquake, resistant to vibrations caused by the wind and its unwanted sounds, complete setup during installation and even after End of installation, minimum use of iron and non-contact aluminium and iron in the facade Thermal shock resistant, super sky and lower cost than traditional materials used in steel building structures.

Table 1. Comparison of the heat transfer coefficient of the sandwich panel with concrete, brick and fiberglass

\begin{tabular}{|c|c|c|c|c|c|c|c|c|c|c|c|}
\hline \multicolumn{9}{|c|}{ Wall Panel Sandwich } & Concrete & Bricks & Fiberglass \\
\hline Thickness (mm) & 35 & 40 & 50 & 60 & 80 & 100 & 150 & 200 & 40 & 40 & 40 \\
\hline heat transfer $(\mathrm{K} / \mathrm{m} 2 \mathrm{k})$ & 0.51 & 0.45 & 0.36 & 0.30 & 0.22 & 0.18 & 0.12 & 0.09 & 16.25 & 14.8 & 0.88 \\
\hline
\end{tabular}




\section{Shapeshel}

The advanced Shapeshel composite is nowadays widely used and increasingly used by architects (Figure 3). Take their imaginative projects. This unique material is used in the building's exterior as an external veneer panel, and can be used in commercial buildings as a focal point for creating a sense of inviting. Shapeshell is made with $3 \mathrm{D}$ CNC and is lightweight. It is resistant to chemical shock and chemical, and it is non-conductive. Another advantage of this material is its anti-flammability certificate in construction facades and full color rendering of this material.
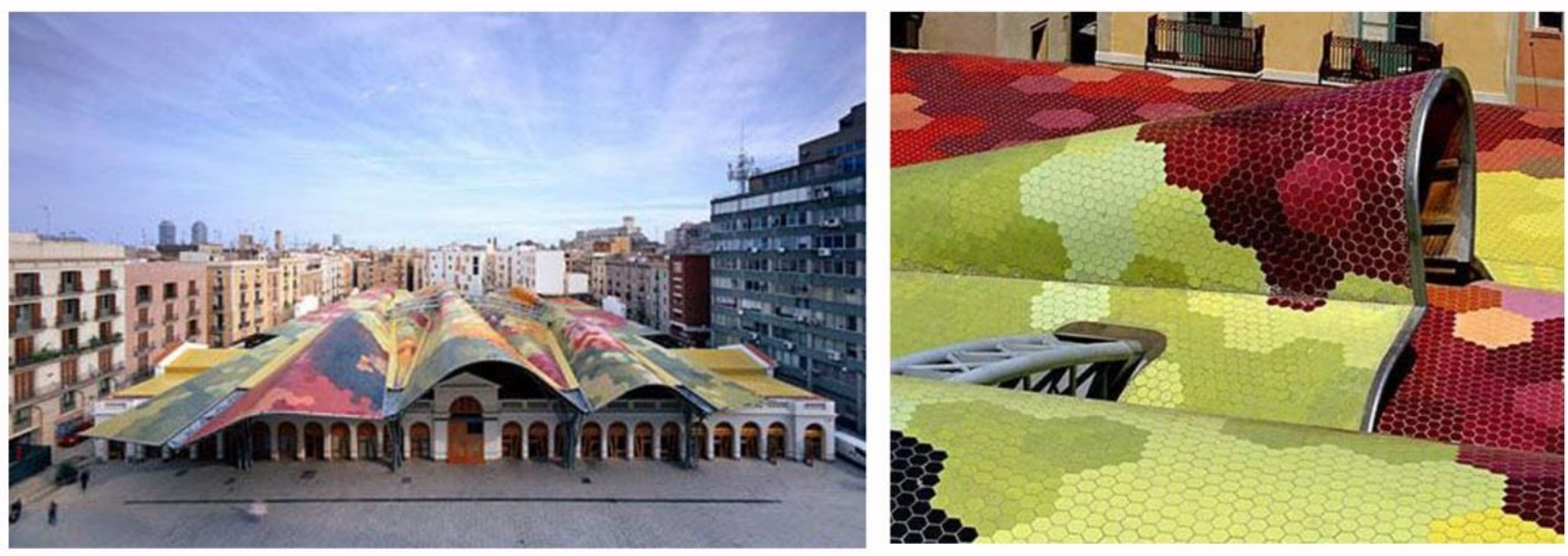

Figure 3: Shape shell composite

\section{Vacuum insulated panel}

By making it possible to create more thin insulating layers than ordinary insulators, they are very suitable for construction applications and reduce the insulation thickness and consequently the thickness of the walls. Compared to traditional insulation materials (polystyrene), the thermal conductivity of these panels is more than ten times lower, which means that with the help of these materials, with the same thickness as traditional insulators, more heat resistance can be created. Brought up In other words, we need a thin layer of insulation to achieve the same thermal resistance

Therefore, new insulators have made it possible to achieve the highest thermal resistance with the thinnest insulating layer possible. The thermal transfer of vips is negligible and only about 4.0-5.0.

The shelf life of the VIP insulation panels is between 20 to 38 years old and in other cases average for 30 to 50 years, which few factors such as panel shell integrity, the amount of vacuum created, seamless quality, and installation affect it.

\section{Smart glass (Figure 4)}

Thermochemical glass. Using thermochemical coatings, you can create a smart glass that prevents heat from blocking light. The ability to cover to change the state between the absorption and reflection of light means using the benefits of solar heating in winter conditions and reflection at higher temperatures and preventing the fading of space. Meanwhile, in both cases, the illuminant light is ideal for lighting the space.

Electrochemical (EC) glass. In this system (EC), the glass unit is replaced by transparent films of thickness from 200 to $300 \mathrm{~nm}$ with varying colour intensities in the visible spectrum from clear to dark blue. The glass unit is connected to the power supply for varying the degree of transparency due to the different amounts of heat transfer. After the flow stops, the optical mode is maintained and there is no need for continuous current. When the glass darkens used, the thermal radiation decreases and therefore most of the radiation passes through the infrared spectrum.

\section{Cellulose coating structure}

This type of coating consists of synthetic fibers, cellulose, construction resins, mineral contaminants, resistant pigments, lubricants and other additives that are used in the form of dough and with the use of flexic acid trowels on the surface. This coating has many properties and can in fact be called the best and most beautiful alternative to paint and wall paper. These types of products are commonly referred to as Belek.

\section{Cellulose coating properties}

It is able to be applied to plaster and mortar in order to cover the underlying defects, moisture and 
refrigeration, the high degree of colour variation, environmental comfort, washing ability, lack of smell and sensitivity, non-cracking, resistance to weathering, anti-static properties, applicability On all types of sub-work, high speed performance, fast and easy repair, fire-retardant, reduced reflection of light, lifespan of high-volume sound (textured surface). Cellulose coating properties is a very good insulating layer for reducing noise disturbance and preventing reflection of sound waves. It is remarkably ( $30 \%$ to $50 \%$ ), which means the environment is acoustic. Lightweight (the weight of this coating is $400-700 \mathrm{gr} / \mathrm{m}$ ), which is much lighter than gypsum weight and colour per square meter ( $17 \mathrm{~kg}$ to $25 \mathrm{~kg}$ ), which reduces the weight of our stomach.

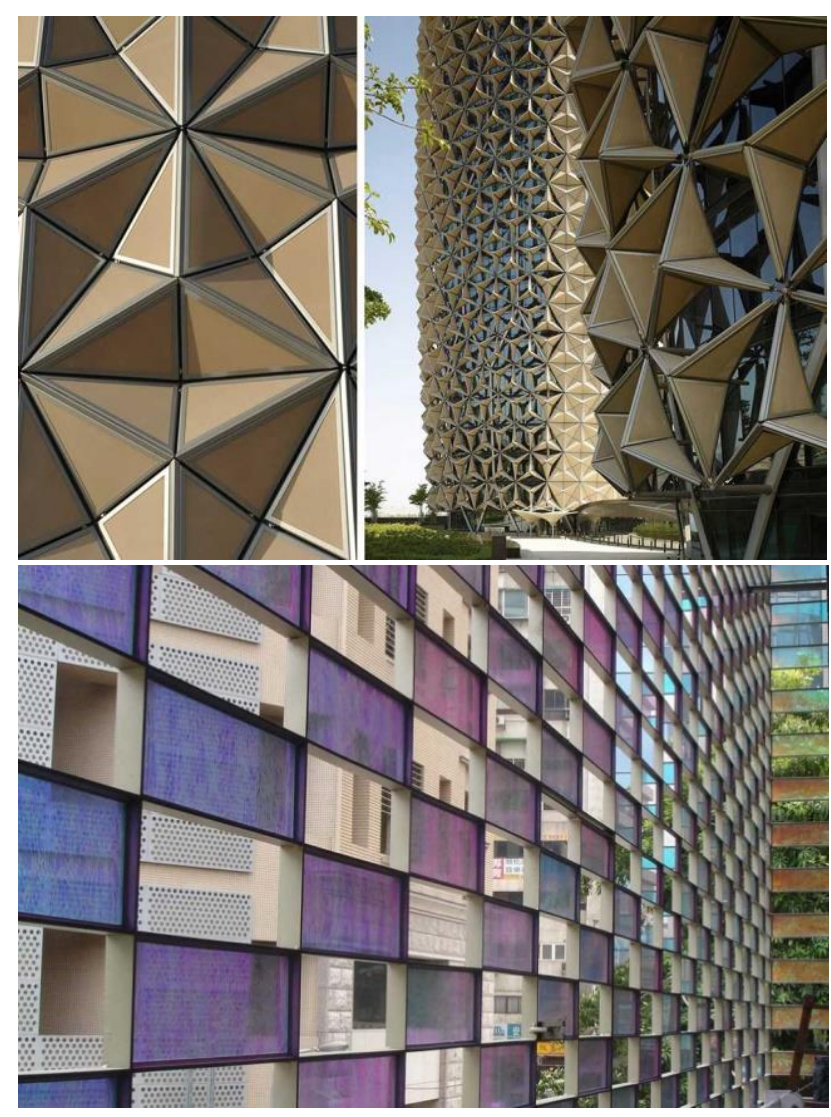

Figure 4: An example of the use of smart glasses

\section{CONCLUSION}

Research on new materials places new horizons in the process of designing and architectural design. Intelligence, and in particular the use of intelligent materials that react to environmental issues, saves, facilitates repair and maintenance of buildings, extends the useful life of more buildings and more innovative architectural designs [2]. The design of a flexible approach to sustainable development is important so that the adaptation of the building to the changing conditions of the users is consistent with the least cost and time with the new conditions and is responsive to a wider range of different needs of the residents. By the supply of intelligent materials, capabilities and lighting facilities will be provided to engineers and designers. The intelligent element, due to the type of application and strength, can contribute to the design and construction of buildings. The use of these materials increases the life of the building from 50 to 100 years and saves the cost of maintenance, which is far more expensive than construction. And the use of this material can reduce the negative environmental impacts and bring society closer to sustainable sustainability criteria.

\section{Competing interests}

The author declares that they have no competing interests.

\section{REFERENCES}

[1] Nazari H, Sotoudeh H, Azad Sola M and Imani Kaleh Sar H (2013). Evaluation of the possibility of localization of materials and modern methods of building industrialization in ceiling, National Conference on Applied Civil Engineering, and recent achievements, Karaj, Sazeh Desert Co., https://www.civilica.com/Paper-ACA01ACA01 305.html

[2] Owen C, Dovey K (2008). Fields of sustainable architecture. The Journal of Architecture. 13(1):9-21. https://doi.org/10.1080/13602360701865373 Google Scholar

[3] Sadiq Ziberi H (2010). Using Intelligent Materials in Building Shells. Fan \& Art Quarterly, Fourteenth, No. 29 (Successive 65): 20-23.

[4] Rogers CA (1995). Intelligent materials. Scientific American. 273(3):154-61. Google Scholar ; https://www.jstor.org/stable/24981766

[5] Vattano S (2014). Smart buildings for A sustainable development. Journal of Economics World. 2: 310324. Google Scholar

[6] Ritter A (2006). Smart materials in architecture, interior architecture and design. Walter de Gruyter; Nov 21, 2006. Google Scholar

[7] Mohamed AS (2017). Smart materials innovative technologies in architecture; towards innovative design paradigm. Energy Procedia. 115:139-54. https://doi.org/10.1016/j.egypro.2017.05.014 Google Scholar

[8] Bach B, Wilhelmer D, Palensky P. Smart buildings, smart cities and governing innovation in the new millennium. In2010 8th IEEE International Conference on Industrial Informatics 2010 Jul 13 (pp. 8-14). IEEE. https://doi.org/10.1109/INDIN.2010.5549478 Google Scholar 
[9] Guy S, Farmer G (2001). Reinterpreting sustainable architecture: the place of technology. Journal of Architectural Education. 54(3):140-8. https://doi.org/10.1162/10464880152632451

Google Scholar 